\title{
Health of the healthcare professionals: A risk assessment study on work-related musculoskeletal disorders in a tertiary hospital, Chennai, India
}

Background: Healthcare profession is known to be at high risk for work related musculoskeletal disorders (WMSDs). It is estimated that almost one-third of all cases of sick leave among healthcare workers are related to WMSDs. Many studies are conducted, which measured the variety of factors across a range of occupations at different levels of risk. However, relation of current exposure to the risk of developing WMSDs is indeed an area to be looked into. Hence, the current study evaluated current exposure and risk of developing WMSDs among different groups of healthcare professionals. Materials and Methods: This was a cross-sectional exposure-risk assessment study, conducted on 140 healthcare professionals, including dentists, laboratory technicians, nurses, physicians and physiotherapists of various clinical departments in a tertiary care hospital in Chennai, India from January to June 2013. Face-to-face interviews and observational analysis of various job tasks were employed. Different combinations of validated and standardized questionnaires were used for collecting different types of data. Results: The exposure and risk assessment on occurrence of WMSDs indicates that nurses are at the highest risk for developing WMSDs, followed by dentists and physiotherapists whereas laboratory technicians and physicians have the least. Among the participants who reported MSDs pain, more than half of the cases were related to work. Conclusion: Among all the healthcare professions, nurses were found to be the high risk group, whereas physicians were found to be the low risk group. We recommend that education, awareness, and training programs on prevention and coping strategies for MSDs be made mandatory for healthcare professionals.

Key words: Exposure, healthcare professionals, risk, work related musculoskeletal disorders

\section{INTRODUCTION}

Work-related musculoskeletal disorders (WMSDs) are responsible for morbidity in many working populations and are known as an important occupational problem with increasing compensation and health costs, reduced productivity, and lower quality of life. ${ }^{[1]}$ WMSDs are reported to significantly impact on quality of life, cause lost work time or absenteeism, increase work restriction, transfer to another job, ${ }^{[2,3]}$ or disability than any other group of diseases ${ }^{[4-6]}$ with a considerable economic toll on the individual, the organization and the society as a whole..$^{[7]}$

In recent years, many studies have been conducted to provide the basis for the risk assessment of the development of WMSDs, ${ }^{[8]}$ which have measured the levels of a variety of factors across a range of occupations at different levels of risk, and investigated the associations with the incidence or prevalence of MSDs for the populations concerned, ${ }^{[9,10]}$ but the association between current exposure and risk of developing WMSDs, is indeed an issue to be looked into.

Healthcare profession is known to be at high risk for WMSDs. ${ }^{[1-13]}$ It is estimated that almost one-third of all cases of sick leave among healthcare workers are related to MSDs. ${ }^{[14]}$ It appears that even in developed countries WMSDs are under-reported among healthcare providers. ${ }^{[15]}$ It is much neglected in 
developing countries. India has been battling traditional public health problems like communicable diseases, malnutrition and inadequate medical care, which are fuelled by fast-growing population, apart from the occupational health problems. ${ }^{[16]} \mathrm{MSD}$ is one of the major occupational health problems in India and estimates have shown that it contributes to about $40 \%$ of all costs towards the treatment of work-related injuries. ${ }^{[17]}$ However, these healthcare professionals, particularly those who are in direct contact with patients, are reported to be vulnerable to acquire MSDs during the course of their work routine. ${ }^{[18,19]}$ These MSDs are reported to be a costly occupational malady among healthcare workers. ${ }^{[20]}$ Most of the previous studies on WMSDs among healthcare workers were limited to any one of the professional groups such as nurses, physical therapists, dentists etc. The current study compared the prevalence and distribution of WMSDs among five different groups of healthcare professionals working in a tertiary-care hospital in Chennai, India, and also evaluated current exposure and risk of developing WMSDs.

\section{MATERIALS AND METHODS}

This was a cross-sectional exposure-risk assessment study, conducted among the healthcare professionals of various clinical departments of a tertiary health-care hospital in Chennai. A nonprobability sampling as convenient to the investigators was employed among dentists, laboratory technicians, nurses, physicians and physiotherapists and ethical clearance was obtained from the Institutional Ethical Committee.

In all the above-mentioned categories, clinicians and clinician-cumacademicians with willingness to take part in the study were included, and those with current trauma and those who refused to participate were excluded. As a result, a total of 140 healthcare professionals were recruited for the study.

Face-to-face interviews as well observational analysis of various job tasks were employed. Different sets of validated and standardized questionnaires were used for collecting different types of data, specific to each professional group. Section-A is a general questionnaire on details of demography, medical and occupational history, diet pattern, lifestyle and personal habits. It also includes questions to determine if the symptoms were workrelated. Section-B is a questionnaire that gathers information about workstation and nature of various job tasks. Section-C is Quick Exposure Check (QEC), an observational method used to assess the level of exposure to ergonomic risks. It gives ordinal scores based on both subjective and objective observations. QEC assesses the back, shoulder/arm, wrist/hand, and neck. The ratings are weighted into scores and added up to summary scores for different body parts and the exposure is assigned an ordinal score between 1 and 4 corresponding to low, moderate, high and very high level respectively. ${ }^{[21,22]}$ Section-D is rapid entire body assessment (REBA) worksheet, an easy-to-use postural analysis tool that gives a quick and logical assessment of risks for WMSDs that may involve the whole body. It provides a suitable method that can be used in healthcare sector and other service industries. ${ }^{[23]}$ REBA provides 5 action levels for estimating the risk level. These action levels starting from 0 to 4 correspond to negligible, low, moderate, high and very high levels of risk respectively. ${ }^{[24]}$ Section-E is the nordic musculoskeletal questionnaire (NMQ), a standardized screening and surveillance tool to find out the body regions affected by musculoskeletal symptoms. In this study, it was used to identify the high risk group for different body regions.

Data descriptive were derived. Univariate analysis compared the demographic variables of the participants with work-related factors. Ergonomic hazards, exposure and risks among the different subgroups were analyzed using independent sample $t$-test for continuous variables, that is, age, height, weight, etc., and Chi-square test was used for analyzing nominal or ordinal variables, that is, sex, smoking habit, etc. Multivariate analysis was conducted on various predictors of MSDs. The results were considered to be significant if $P \leq 0.05$. The data analysis was carried out using the software $\mathrm{R}$ version 3.0.1. ${ }^{[25]}$

\section{RESULTS}

The mean \pm standard deviation of age, height, weight and body mass index of all respondents were $32.5 \pm 8.1$ years, $1.6 \pm 0.1 \mathrm{~m}$, $66.5 \pm 13.4 \mathrm{~kg}$ and $24.9 \pm 4.3 \mathrm{~kg} / \mathrm{m}^{2}$ respectively. The total years of experience and total working hours per week was found to be $8.6 \pm 8.1$ years, $48 \pm 4 \mathrm{~h}$ respectively. The descriptive information of all respondents is presented in Table 1.

This study population contains $64.3 \%$ (41.4\% male and 58.6\% female) of exclusive clinical practitioners and $35.7 \%$ of those who are both clinical practitioners as well as academicians. Among all, laboratory technicians are the only professionals who are exclusively clinical with respect to their job, whereas all others included both clinicians as well as clinician-cum-academicians. Among all, 68.5\% of the participants were married. Only $3.6 \%$ of the participants were smokers and $8.6 \%$ were alcoholics. Of all, $35 \%$ were involved in other types of physical activities like sports, exercises and yoga routinely, whereas only $12.2 \%$ take part in recreational activities out of working schedule. In this study population, $61.4 \%$ of the participants work in a single-shift duty of $8 \mathrm{~h}$ duration, whereas

\begin{tabular}{|c|c|c|c|c|}
\hline Variables & Minimum & Maximum & Median & Mean \pm SD \\
\hline Age (years) & 21 & 73 & 30 & $32.5 \pm 8.1$ \\
\hline Height (m) & 1.3 & 1.8 & 1.6 & $1.6 \pm 0.1$ \\
\hline Weight (kg) & 35 & 103 & 67 & $66.5 \pm 13.4$ \\
\hline BMI $\left(\mathrm{kg} / \mathrm{m}^{2}\right)$ & 14.3 & 38.7 & 25.1 & $24.9 \pm 4.3$ \\
\hline $\begin{array}{l}\text { Total work } \\
\text { experience (years) }\end{array}$ & 0.2 & 50 & 6 & $8.6 \pm 8.1$ \\
\hline $\begin{array}{l}\text { Expreice in study } \\
\text { org (years) }\end{array}$ & 0.2 & 25 & 4.5 & $6.6 \pm 6.2$ \\
\hline $\begin{array}{l}\text { Total working } \\
\text { hours/week (h) }\end{array}$ & 30 & 60 & 48 & $48 \pm 4$ \\
\hline
\end{tabular}

$\mathrm{SD}=$ Standard deviation, $\mathrm{BMI}=$ Body mass index 
$38.6 \%$ work in 3 shifts, the shift duration being $6 \mathrm{~h}$ in the morning, $6 \mathrm{~h}$ in the evening and $12 \mathrm{~h}$ in the night. Most of the participants $(77.1 \%)$ work in the same station as there is no job rotation, whereas the rest of them $(22.9 \%)$ have job rotation once in 3 months or biannually as shown. In general, participants in the musculoskeletal complaint group were younger, obese and had lesser years of experience, but more working hours per shift and exclusively clinical. There were no statistically significant differences in terms of smoking, alcoholism and physical/recreational activities between the two groups having MSDs pain and not as shown in Table 2.

Among all participants, the most common ergonomic hazards reported were prolonged sitting, standing, forward bending of trunk and neck flexion, whereas lifting, pulling or pushing at work and repetitive and/or forceful work were the least common reported issues. Univariate analysis done to compare ergonomic hazards between participants "with MSDs" and "without MSDs" showed a longer duration of exposure to ergonomic factors for the group "with MSDs," though it was statistically nonsignificant. Among those "with MSDs," $83 \%$ reported that forward bending of trunk is a major hazard in their workplace, followed by neck flexion $(75 \%)$. Even those "without MSDs" reported forward bending of trunk $(85 \%)$ as a major hazard, followed by prolonged standing $(70 \%)$ and sitting $(60 \%)$. Details of all other hazards reported by the participants are shown in Table 3.

The self-reported ergonomic hazards among different participants indicates that, nurses reported high incidence of all ergonomic hazards followed by physiotherapists and dentists. Laboratory technicians and physicians reported the least for most of the ergonomic hazards.

Analysis of QEC responses indicates that nurses (41.70\%) are at the highest level of exposure, followed by physiotherapists $(35 \%)$ and dentists $(22.6 \%)$. Physicians and lab technicians are the least exposed, at $4 \%$ in their respective workstations. Similarly, postural risk analysis too shows high risk among nurses (44.5\%), followed by dentists $(51.7 \%)$ and physiotherapists $(50 \%)$. The details of current exposure and risk levels among different participants are shown in Figure 1. The correlation coefficients for final scores of QEC

\begin{tabular}{|c|c|c|c|c|c|c|}
\hline Predictors & Category & Total $(n=140)(\%)$ & Without MSDs $(n=69)(\%)$ & With MSDs $(n=71)(\%)$ & OR & $P$ \\
\hline \multirow[t]{3}{*}{ Age } & $<30$ years & $72(51.4)$ & $34(49.2)$ & $38(53.5)$ & Reference & 0.343 \\
\hline & $30-50$ years & $65(46.4)$ & $34(49.2)$ & $31(43.6)$ & 0.8 & \\
\hline & $>50$ years & $3(2.2)$ & $1(1.5)$ & $2(2.8)$ & 0.3 & \\
\hline \multirow[t]{2}{*}{ Sex } & Male & $58(41.4)$ & $34(49.2)$ & $24(33.8)$ & Reference & 0.091 \\
\hline & Female & $82(58.6)$ & $35(50.7)$ & $47(66.2)$ & 1.9 & \\
\hline \multirow[t]{4}{*}{ BMI } & Under weight & $10(7.1)$ & $6(8.7)$ & $4(5.6)$ & Reference & 0.462 \\
\hline & Normal & $39(27.8)$ & $16(23.2)$ & $23(32.3)$ & 2.16 & \\
\hline & Over weight & $21(15)$ & $9(13.1)$ & $12(16.9)$ & 2 & \\
\hline & Obese & $70(50)$ & $38(55.1)$ & $32(45.1)$ & 1.26 & \\
\hline \multirow[t]{2}{*}{ Marital status } & Married & $96(68.5)$ & $48(69.5)$ & $48(67.6)$ & Reference & 0.946 \\
\hline & Unmarried & $44(31.5)$ & $21(30.4)$ & $23(32.4)$ & 1.1 & \\
\hline \multirow[t]{2}{*}{ Area of practice } & Clinical & $90(64.2)$ & $42(60.8)$ & $48(67.6)$ & Reference & 0.512 \\
\hline & $\begin{array}{l}\text { Clinical and } \\
\text { academics }\end{array}$ & $50(35.7)$ & $27(39.1)$ & $23(32.4)$ & 1.1 & \\
\hline \multirow[t]{4}{*}{ Experience } & $<5$ years & $65(46.4)$ & $36(52.1)$ & $29(40.8)$ & Reference & 0.331 \\
\hline & $5-10$ years & $35(25)$ & $18(26.1)$ & $17(23.9)$ & 1.17 & \\
\hline & $10-15$ years & $15(10.7)$ & $5(7.2)$ & $10(14.1)$ & 2.48 & \\
\hline & $>15$ years & $25(17.8)$ & $10(14.5)$ & $15(21.1)$ & 1.86 & \\
\hline \multirow[t]{2}{*}{ Physical activity } & No & $91(65)$ & $40(57.9)$ & $51(71.8)$ & Reference & 0.123 \\
\hline & Yes & $49(35)$ & $29(42.1)$ & $20(28.1)$ & 1.85 & \\
\hline \multirow{2}{*}{$\begin{array}{l}\text { Recreational } \\
\text { activity }\end{array}$} & No & $123(87.8)$ & $59(85.5)$ & $64(90.1)$ & Reference & 0.561 \\
\hline & Yes & $17(12.2)$ & $10(14.4)$ & 7 (9.8) & 0.65 & \\
\hline \multirow[t]{2}{*}{ Smoking } & No & $135(96.4)$ & $64(92.7)$ & $70(98.6)$ & Reference & 0.063 \\
\hline & Yes & $5(3.6)$ & $4(7.2)$ & $1(1.4)$ & 0.25 & \\
\hline \multirow[t]{2}{*}{ Alcoholism } & No & $128(91.4)$ & $60(86.9)$ & $68(95.7)$ & Reference & 0.118 \\
\hline & Yes & $12(8.6)$ & $9(13.1)$ & $3(4.3)$ & 0.29 & \\
\hline \multirow[t]{2}{*}{ Shift } & Single & $86(61.4)$ & $43(62.3)$ & $43(60.6)$ & Reference & 0.968 \\
\hline & More & $54(38.6)$ & $26(37.6)$ & $28(39.4)$ & 1.08 & \\
\hline \multirow[t]{2}{*}{ Job rotation } & No & $108(77.1)$ & $52(75.3)$ & $56(78.8)$ & Reference & 0.769 \\
\hline & Yes & $32(22.9)$ & $17(24.6)$ & $15(28.2)$ & 0.82 & \\
\hline \multirow[t]{3}{*}{ Stress } & Low & $31(22.1)$ & $21(30.4)$ & $10(14.1)$ & Reference & 0.36 \\
\hline & Moderate & $63(45)$ & $27(39.1)$ & $36(50.7)$ & 0.3 & \\
\hline & High & $46(32.9)$ & $21(30.4)$ & $25(35.2)$ & 0.85 & \\
\hline
\end{tabular}

$\mathrm{OR}=$ Odds ratio, MSDs = Musculoskeletal disorders, $\mathrm{BMI}=$ Body mass index 
exposure levels and REBA risk levels was $=0.71$. The association between exposure and risk was found to be significant as the $P<$ $0.05(r=0.71)$.

About $80 \%$ of participants have high exposure levels and are at high risk of developing WMSDs. Among all participants, nurses are the highest exposed (48\%) as well as at highest risk (33\%), followed by dentists (exposure - 24\%, risk - 33\%) and physiotherapists having both exposure and risk at $22 \%$. While both physicians and laboratory technicians have same exposure (3\%), the risk among lab technicians is high $(7 \%)$ as compared to physicians (5\%), indicated in Figure 2.

About half (50.7\%) of the participants reported symptoms at least in one part of their bodies over the past 12 months. Among these, low back pain was the highest $(45.7 \%)$, followed by neck pain (28.5\%) and shoulder pain (23.5\%). Elbow pain (5\%), hip/thigh pain $(7.1 \%)$ was the least reported among all participants, as shown in Figure 3. Irrespective of the regions, approximately $56 \%$ of nurses complained of body pain in the last 12 months, followed by $55 \%$ of physiotherapists, $54 \%$ of dentists, $39 \%$ of lab technicians and $38 \%$ of physicians.

Musculoskeletal pain was complained by $50.7 \%$ of all participants, and work-relatedness was found in $26.40 \%$ indicating that job factors are major contributors for MSDs. Moreover, work-related pain was found to be high in nurses, dentists and physiotherapists, whereas physicians and laboratory technicians reported nonwork related pain as shown in above Figure 4.

The correlation coefficients for final REBA Risk scores with complaints of work-related musculoskeletal pain was found to be significant $(r=0.41$ and $P=0.002)$. It indicates that with increase in risk score chance of getting body pain also increases if the person continues to work in the same workstation.

\section{DISCUSSION}

From this study, a correlation was found between occupational factors and incidence of WMSDs among the healthcare workers, which indicates that certain healthcare professions are at high ergonomic risk. Though MSDs found to be related to work in $26.4 \%$ of the participants is lesser than a previous study among tertiary healthcare workers by Emmanuel et al. ${ }^{[26]}$ which reported workrelatedness at $68.7 \%$, it indicates the seriousness of the problem. The finding that low back pain $(45.70 \%)$ was the predominant complaint, followed by neck pain $(28.50 \%)$, shoulder pain $(23.50 \%)$ and knee and ankle pain (20\%), shows that low back pain is the prevailing

\begin{tabular}{|c|c|c|c|c|c|}
\hline Ergonomic hazards & Total $(n=140)(\%)$ & Without MSDs $(n=69)(\%)$ & With MSDs $(n=71)(\%)$ & $P$ & OR $(95 \% \mathrm{Cl})$ \\
\hline Neck flexion more than $20^{\circ}$ & $100(71)$ & $46(68)$ & $54(75)$ & 0.44 & $1.38(0.66-2.88)$ \\
\hline Arm level higher than shoulder & $28(20)$ & $14(21)$ & $14(19)$ & 0.97 & $0.96(0.42-2.21)$ \\
\hline Repetitive work more than $4 / \mathrm{min}$ & $70(50)$ & $32(47)$ & $38(53)$ & 0.62 & $1.19(0.61-2.3)$ \\
\hline Forceful work & $42(30)$ & $23(34)$ & $19(26)$ & 0.43 & $0.73(0.35-1.51)$ \\
\hline Forward bending of trunk & $118(84)$ & $58(85)$ & $60(83)$ & 0.93 & $0.83(0.33-2.08)$ \\
\hline $\begin{array}{l}\text { Lateral bending or twisting } \\
\text { of trunk }\end{array}$ & $71(51)$ & $34(5)$ & $37(51)$ & 0.99 & $1.12(0.58-2.17)$ \\
\hline $\begin{array}{l}\text { Prolonged sitting (more than } \\
20 \text { min) }\end{array}$ & $87(62)$ & $41(60)$ & $46(64)$ & 0.79 & $1.11(0.56-2.2)$ \\
\hline $\begin{array}{l}\text { Prolonged standing (more than } \\
20 \text { min) }\end{array}$ & $93(66)$ & $48(71)$ & $45(63)$ & 0.41 & $0.67(0.33-1.35)$ \\
\hline Lifting, pulling or pushing & $38(27)$ & $21(31)$ & $17(24)$ & 0.43 & $0.72(0.34-1.52)$ \\
\hline
\end{tabular}

$\mathrm{OR}=$ Odds ratio, $\mathrm{Cl}=$ Confidence interval, $\mathrm{MSD}$ = Musculoskeletal disorders

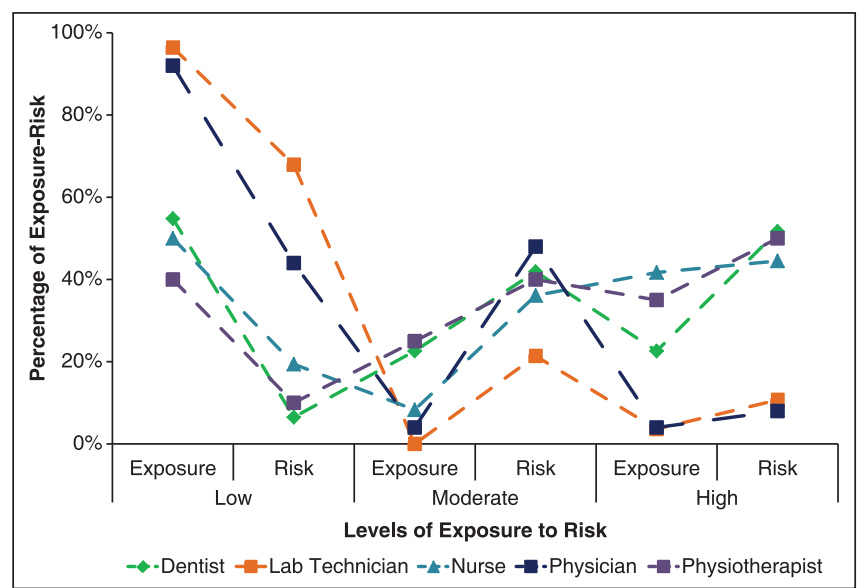

Figure 1: Current exposure to risk levels among all participants

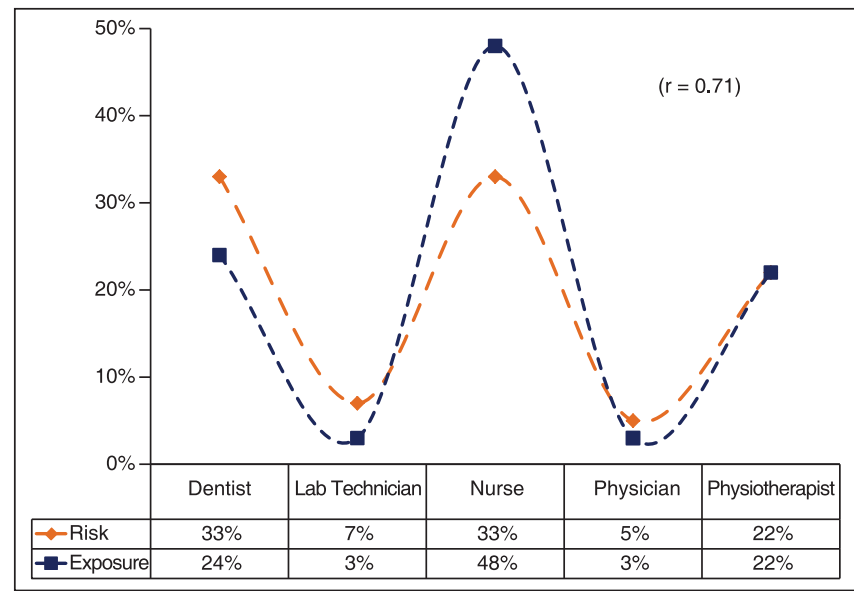

Figure 2: Correlation of exposure to risk levels of all participants 


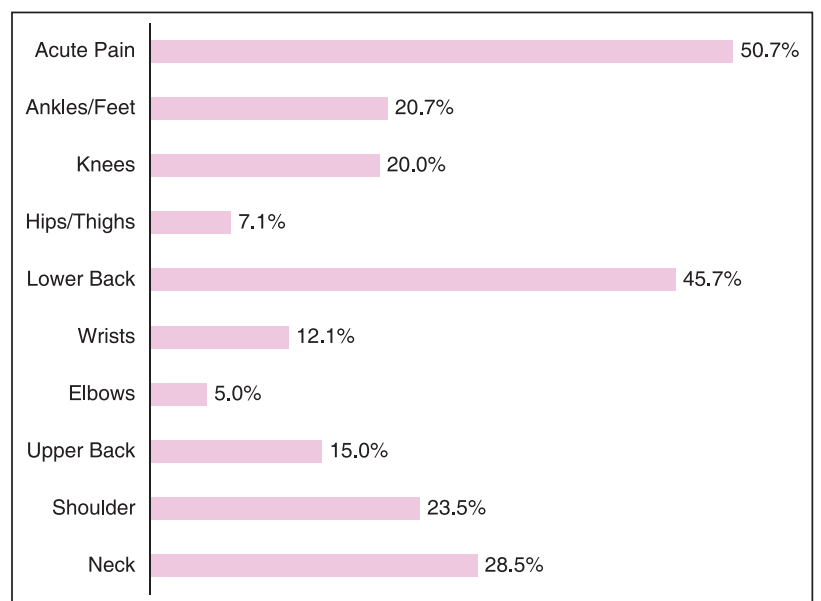

Figure 3: Relative frequency of musculoskeletal disorders among all participants

problem in healthcare industry too. The least of complaints were reported at wrist $(12 \%)$, hip/thigh $(7.10 \%)$ and elbow (5\%), which supports the study results of Emmanuel et al. The gender pattern in the occurrence of WMSDs found in this study is similar to the result of most studies. Many previous studies reported a female predominance in the prevalence of MSDs in both the general population ${ }^{[26,27]}$ and working population. ${ }^{[15,28]}$ In this study, it was found that female healthcare professionals have 1.9 times higher risk (odds ratio $[\mathrm{OR}]=1.9$ ) for developing MSDs than male healthcare professionals. It was also found that over-weight $(\mathrm{OR}=2)$ and obese $(\mathrm{OR}=1.26)$ professionals have a greater chance of developing WMSDs. But the age group distribution and work experience reveals that younger age group of $<30$ years, with $<5$ years of professional experience have a greater chance of developing WMSDs [Table 2], which supports the study findings of Cromie et al., ${ }^{[29]}$ but is opposed to the study by Tinubu et al. ${ }^{[28]}$ It may be due to lack of orientation to the workstation and/or vigorous working style of the youngsters as compared to the older professionals, who are well adapted to the work station and mostly follow safe working principles. Those professionals involved in both clinical as well as academic (operational definition) work have 1.1 times higher chance of developing WMSDs when compared to those who are exclusively involved in clinical work. The participants who work in shifts have greater chance of developing WMSDs $(\mathrm{OR}=1.08)$ as compared to those who work in single shift $(61.4 \%)$, which is similar to the result of a previous study by Shafiezadeh $e t$ al. ${ }^{[0]}$ This study shows that job rotation may protect the worker from the risk of developing WMSDs. The participants who are involved actively in other physical activities have 1.85 times greater chance of developing WMSDs than the others. This is in consistence with previous findings. ${ }^{[29]}$ All the demographic variables in our study was found to be nonsignificant for developing WMSDs as $P$ value was not $<0.05$ in any of those.

Ergonomic hazards such as forward bending of trunk $(82.2 \%)$, neck flexion of $>20^{\circ}(71.4 \%)$ and prolonged standing/sitting (66\%) have significantly contributed to the development of pain in back and neck, among our study participants. The fact that high exposure

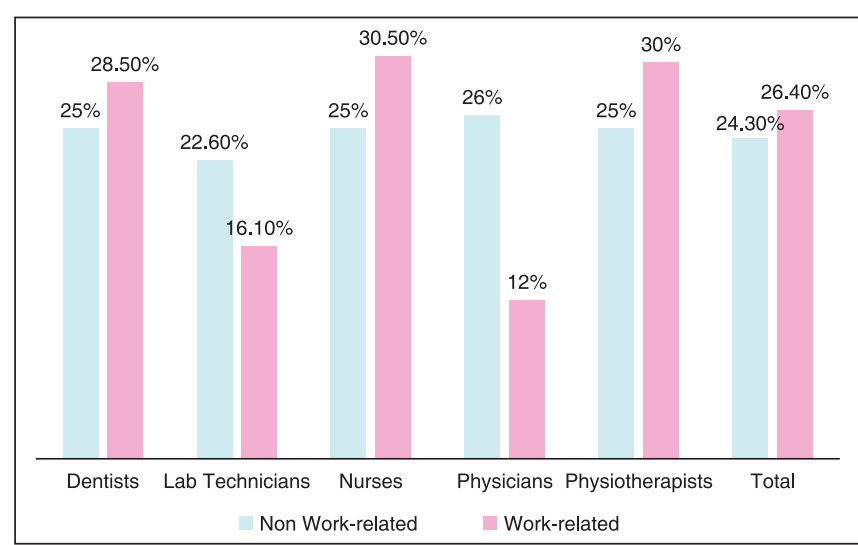

Figure 4: Musculoskeletal pains and work-relatedness among all participants

leads to high risk which in turn will result in higher prevalence of the problem/disorder/disease is proved by the strong association between exposure and risk $(r=0.71)$, and that between risk and WMSDs $(r=0.41)$. In addition, the musculoskeletal symptoms were also related to ergonomic hazards as well as job risk factors among healthcare professionals.

The highest incidence of WMSDs was found among nurses $(55.5 \%)$, followed by physiotherapists $(55 \%)$, dentists $(53.5 \%)$, lab technicians (38.7\%) and then the physicians (38\%). The result of this study is similar to a previous study by Karahan et al. ${ }^{[31]}$ who assessed the prevalence and risk factors for low back pain amongst a variety of Turkish hospital workers including nurses, physicians, physical therapists, technicians, secretaries and hospital aides, in which the highest prevalence was reported by nurses (77.1\%). Similarly, the study by Emmanuel et al. found that the highest WMSDs prevailed among nurses (30.4\%), followed by doctors and other sub-staff and the study by Bolanle Tinubu et al. ${ }^{[28]}$ found $78 \%$ prevalence among Nigerian nurses. Several authors have reported high prevalence of WMSDs among nurses from the developed countries. ${ }^{[32]}$ The major complaint from nurses was hip/thigh pain (60\%), followed by ankle/feet (55\%) and knees (53\%). In the present study, though the most common ergonomic hazards reported by nurses were forward bending of trunk (97.2\%), neck flexion of $>20^{\circ}(83.3 \%)$ and prolonged standing for $>20$ min $(80.6 \%)$, complaints of neck pain and/or back pain were proportionately less. However, this finding is inconsistent with the findings of the study by Bolanle Tinubu et al. ${ }^{[28]}$ Back and neck were the most commonly exposed regions among nurses that accounts for $48 \%$ risk of developing WMSDs.

In dentists, prolonged sitting posture $(90.3 \%)$, neck flexion of $>20^{\circ}(87.1 \%)$, forward bending of trunk $(80.6 \%)$ and repetitive work $(71 \%)$ are inherent professional risk factors. Similar to the results obtained from the previous studies, the most frequent MSDs were reported in the shoulder (39.4\%) followed by upper back $(38.1 \%)$, neck region $(37.5 \%)$ and wrist (29.4\%). Also, the findings regarding work position in dentists reported by Kierklo et al. ${ }^{[33]}$ are consistent with our results. The above-reported body 
region pain correlates well with exposure analysis among dentists (neck region exposure was as high as $45.2 \%$ ). Even though only $22.6 \%$ dentists have higher exposure, the inherent professional ergonomic issue place them at a higher risk of 33\% for developing WMSDs.

The present study found that the major ergonomic hazards for physiotherapists are forward bending of trunk (100\%), neck flexion (95\%) and prolonged standing (85\%), which is consistent with findings of previous studies. ${ }^{[34,35]}$ It is noteworthy that some of these risk factors are inherent to the job nature of physiotherapy professionals. In the current study, though only $35 \%$ of physiotherapists are highly exposed, addition of physically demanding risk factors to this exposure, has resulted in a situation wherein $50 \%$ of physiotherapists are at high risk of developing WMSDs. Although it may be possible to adopt strategies that would reduce some of the risks, it would be unrealistic to expect a complete abolition of risk. With respect to the affected body regions, the highest incidence of MSDs is in the elbow (28.6\%) and wrist (23.5\%), as most of the physiotherapists use manipulative techniques for longer periods and repetitively. This is followed by neck pain (22.5\%) and back pain (18.8\%). This is inconsistent with the findings of a previous study conducted by Salik et al., ${ }^{[34]}$ in which back pain $(26 \%)$ was the predominant complaint followed by wrist pain $(18 \%)$. At the same time, it is highly consistent with the findings of another study by Cromie et al. ${ }^{[29]}$ which showed that increased prevalence of wrist/thumb symptoms was associated with the use of mobilization and manipulation techniques.

In the present study, the percentage of laboratory technicians who complained of symptoms was low $(21.1 \%)$, as compared to those obtained by other authors. However, among the studies focusing on laboratory workers, only Kilroy and Dockrell ${ }^{[35]}$ described the global prevalence of symptoms, but they considered the period of the preceding 3 months as against the period of 12 months in the present study. Among this group, shoulder pain (18.2\%) was the chief complaint followed by neck pain (17.5\%), back pain $(15.6 \%)$ and wrist pain $(11.8 \%)$. The major ergonomic hazards were forward bending of trunk (85.7\%) and prolonged sitting/standing posture (64\%). As for the results obtained through the ergonomic workplace analysis, there was a predominant association between occurrence of musculoskeletal symptoms and working postures. This group of healthcare professionals are the least exposed (3.60\%), and $10.70 \%$ of laboratory technicians fall under high risk group. It may not be negligible and can be minimized with proper education of laboratory ergonomics.

Compared to the study by Mehrdad et al. ${ }^{[27]}$ as well as to other studies on healthcare professionals, in the present study, MSDs reported by physicians was much lower (18.3\%). Elbow pain (28\%), back pain $(19 \%)$, and shoulder and wrist pain $(12 \%)$ were the main complaints. The major ergonomic hazards reported were prolonged sitting $(80 \%)$, neck flexion of $>20^{\circ}(64 \%)$ and repetitive work $(52 \%)$. This group has a risk of only $8 \%$ for developing WMSDs because of lesser exposure and lack of ergonomically hazardous tasks. Overall, the incidence of MSDs among these physicians is similar to that of the general population, which is $18 \%$ for low back pain and $7 \%$ for neck pain.

\section{CONCLUSION}

A high proportion of healthcare professionals reported WMSDs at one or the other body region, low back being the most commonly affected area. The exposure analysis reveals that nurses are the highest exposed professionals followed by physiotherapists and dentists, whereas the lab technicians and physicians were the least exposed. The risk assessment and occurrence of WMSDs also indicate that nurses have the highest risk for developing WMSDs, followed by dentists and physiotherapists, whereas the lab technicians and physicians have not only the least risk for developing WMSDs, but also the lowest incidence of current MSDs pain. Hence this study concludes that among the healthcare professionals assessed in this ergonomic study, nurses were found to be the high risk group, with highest exposure to hazards whereas physicians were found to be the low risk group with minimal exposure in their respective workstations.

The nonprobability sampling method employed in this study prevents the generalization of results. Since the questionnaires on ergonomic hazards used in this study are self-reported, there are chances for subjective bias. Also, the work postures were observed only once for a brief period of about 15 min for each subject, which might give an incorrect risk status.

A better planned long-term study eliminating limitations of the current study and using quantitative analytical tools may give a more accurate estimate of WMSDs and exposure-to-risk levels among healthcare professionals, and thereby a better means to accurately recommend and implement policies and strategies to combat this serious issue of WMSDs among healthcare professionals. The future work may be extended to include other categories of healthcare professionals as well as other professionals involved in healthcare industry who are at high risk for WMSDs like janitors, ward boys, sanitary workers, emergency personnel, etc.

We recommend that education, awareness and training programs on prevention and coping strategies for MSDs be made mandatory for healthcare professionals especially for the high risk groups such as nurses, dentists and physiotherapists in order to reduce the occurrence of WMSDs among them not only for their better health but also, importantly to promote efficiency in patient care. An integrated health promotion model should be planned for healthcare professionals.

\section{ACKNOWLEDGMENT}

We are thankful to participants of the study who gave us unconditional support and QEC, REBA, NMQ team to use the scale in this study. 


\section{REFERENCES}

1. Karwowski W, Marras WS. Occupational Ergonomics: Principles of Work Design. Florida: CRC Press; 2003.

2. Aptel M, Aublet-Cuvelier A, Cnockaert JC. Work-related musculoskeletal disorders of the upper limb. Joint Bone Spine 2002;69:546-55.

3. Kilbom A. Editorial/Prevention of work-related musculoskeletal disorders in the workplace. Int J Ind Ergon 1998;21:1-3.

4. Badley EM, Rasooly I, Webster GK. Relative importance of musculoskeletal disorders as a cause of chronic health problems, disability, and healthcare utilization: Findings from the 1990 Ontario Health Survey. J Rheumatol 1994;3:505-14.

5. Riihimäki H. Hands up or back to work - Future challenges in epidemiologic research on musculoskeletal diseases. Scand J Work Environ Health 1995;21:401-3.

6. Leijon M, Hensing G, Alexanderson K. Gender trends in sick-listing with musculoskeletal symptoms in a Swedish county during a period of rapid increase in sickness absence. Scand J Soc Med 1998;26:204-13.

7. Kemmlert K. Labour Inspectorate Investigation for the Prevention of Occupational Musculoskeletal Injuries (licentiate thesis). Solna, Sweden: National Institute of Occupational Health 1994.

8. Colombi D, Occhipinti E, Grieco A. Risk Assessment and Management of Repetitive Movements and Exertions of Upper Limbs. Oxford: Elsevier; 2002.

9. Safety of Machinery-Human Physical Performance-Part 4.Evaluation of Working Postures in Relation to Machinery. PrEN1005-4. Republic of Bulgaria, 2009. Assessed from- https://law.resource.org/pub/bg/ibr/bds. en.1005-4.2005.a1.2008.pdf.

10. Campo M, Weiser S, Koenig KL, Nordin M. Work-related musculoskeletal disorders in physical therapists: A prospective cohort study with 1-year follow-up. Phys Ther 2008;88:608-19.

11. Smith DR, Wei N, Ishitake T, Wang RS. Musculoskeletal disorders among Chinese medical students. Kurume Med J 2005;52:139-46.

12. Thornton LJ, Barr AE, Stuart-Buttle C, Gaughan JP, Wilson ER, Jackson $\mathrm{AD}$, et al. Perceived musculoskeletal symptoms among dental students in the clinic work environment. Ergonomics 2008;51:573-86.

13. Smith DR, Leggat PA. Musculoskeletal disorders among rural Australian nursing students. Aust J Rural Health 2004;12:241-5.

14. Alexopoulos EC, Stathi IC, Charizani F. Prevalence of musculoskeletal disorders in dentists. BMC Musculoskelet Disord 2004;5:16.

15. Salik Y, Ozcan A. Work-related musculoskeletal disorders: A survey of physical therapists in Izmir-Turkey. BMC Musculoskelet Disord 2004;5:27.

16. European Agency for Safety and Health at Work. Work-related neck and upper limb musculoskeletal disorders, 1999. National Research Council. Musculoskeletal disorders and the workplace. The Robens Centre for Health Ergonomics European Institute of Health \& Medical Sciences University of Surrey Guildford, Surrey, U.K. Assessed from -https://osha. europa.eu/en/publications/reports/201.

17. European Agency for Safety and Health at Work Fact Sheet. Available from: http://www.osha.europa.eu. Available from: [Last accessed on 2012 Dec 12].

18. Lorusso A, Bruno S, L'Abbate N. Musculoskeletal complaints among Italian X-ray technologists. Ind Health 2007;45:705-8.

19. Ylipää V, Szuster F, Spencer J, Preber H, Benko SS, Arnetz BB. Health, mental well-being, and musculoskeletal disorders: A comparison between Swedish and Australian dental hygienist. J Dent Hyg 2002;76:47-58.

20. Meijsen P, Knibbe HJ. Work-related musculoskeletal disorders of perioperative personnel in the Netherlands. AORN J 2007;86:193-208.

21. Li G, Buckle P. Evaluating Change in Exposure to Risk for Musculoskeletal Disorders - A Practical Tool. HSE. Available from: [Last accessed on 2011 Apr 19].

22. David G, Woods V, Li G, Buckle P. The development of the Quick Exposure Check (QEC) for assessing exposure to risk factors for workrelated musculoskeletal disorders. Appl Ergon 2008;39:57-69.

23. Hignett $S$, McAtamney L. Rapid entire body assessment (REBA). Appl Ergon 2000;31:201-5.

24. McAtamney L, Nigel Corlett E. RULA: a survey method for the investigation of work-related upper limb disorders. Appl Ergon 1993;24:91-9.

25. R Core Team (2013). R: A language and environment for statistical computing. R Foundation for Statistical Computing, Vienna, Austria. URL http://www.R-project.org/.

26. Emmanuel C, Obembe AO, Bamidele S. Work-related musculoskeletal disorders among health workers in a Nigerian Teaching Hospital. TAF Prev Med Bull 2012;11:583-8.

27. Mehrdad R, Dennerlein JT, Morshedizadeh M. Musculoskeletal disorders and ergonomic hazards among Iranian physicians. Arch Iran Med 2012;15:370-4.

28. Tinubu BM, Mbada CE, Oyeyemi AL, Fabunmi AA. Work-related musculoskeletal disorders among nurses in Ibadan, South-west Nigeria: A cross-sectional survey. BMC Musculoskelet Disord 2010;11:12.

29. Cromie JE, Robertson VJ, Best MO. Work-related musculoskeletal disorders in physical therapists: Prevalence, severity, risks, and responses. Phys Ther 2000;80:336-51.

30. Shafiezadeh KR. Prevalence of Musculoskeletal Disorders among Paramedics Working in a Large Hospital in Ahwaz, Southwestern Iran. IJOEM 2011;2:3.

31. Karahan A, Kav S, Abbasoglu A, Dogan N. Low back pain: prevalence and associated risk factors among hospital staff. J Adv Nurs. 2009; 65: 516-24.

32. Ando S, Ono Y, Shimaoka M, Hiruta S, Hattori Y, Hori F, et al. Associations of self estimated workloads with musculoskeletal symptoms among hospital nurses. Occup Environ Med 2000;57:211-6.

33. Kierklo A, Kobus A, Jaworska M, Botulinski B. Work-related musculoskeletal disorders among dentists - A questionnaire survey. Ann Agric Environ Med 2011;18:79-84.

34. Salik Y, Ozcan A. Work-related musculoskeletal disorders: A survey of physical therapists in Izmir-Turkey. BMC Musculoskelet Disord 2004; 5: 27.

35. Kilroy N, Dockrell S. Ergonomic intervention: Its effect on working posture and musculoskeletal symptoms in female biomedical scientists. $\mathrm{Br} \mathrm{J}$ Biomed Sci 2000;57: 199-206.

How to cite this article: Yasobant S, Rajkumar P. Health of the healthcare professionals: A risk assessment study on work-related musculoskeletal disorders in a tertiary hospital, Chennai, India. Int J Med Public Health 2015;5:189-95.

Source of Support: Nil, Conflict of Interest: None declared. 